\title{
DOSSIER
}

\section{LA GRAN GUERRA EN ESPAÑA: POLÉMICAS INTELECTUALES E IMPACTO POLÍTICO Y SOCIAL}

\author{
Maximiliano Fuentes Codera \\ Universitat de Girona \\ maximiliano.fuentes@udg.edu
}

The Great War in Spain: Intellectual polemics and political and social impact

Recibido: 11/06/2016 - Aceptado: 19/10/2016

Cómo citar este artículo/Citation:

Maximiliano FUENTES CODERA (2017), "La Gran Guerra en España: polémicas intelectuales e impacto político y social", Hispania Nova, 15, págs. 373-393,

DOI: https://doi.org/10.20318/hn.2017.3494
Copyright: (C) HISPANIA NOVA es una revista debidamente registrada, con ISSN 1138-7319 y Depósito Legal M 9472-1998. Los textos publicados en esta revista están -si no se indica lo contrario- bajo una licencia Reconocimiento-Sin obras derivadas 3.0 España de Creative Commons. Puede copiarlos, distribuirlos y comunicarlos públicamente siempre que cite su autor y la revista y la institución que los publica y no haga con ellos obras derivadas. La licencia completa se puede consultar en: http://creativecommons.org/licenses/by-nd/3.0/es/deed.es
Resumen: Este artículo se propone analizar el impacto político y social de los conocidos debates entre aliadófilos y germanófilos que dominaron España durante la Primera Guerra Mundial. Además de estudiar los vínculos entre los planteamientos intelectuales y los diversos grupos políticos en las grandes ciudades, se aproxima a un estudio de caso, el de las comarcas gerundenses, para poner de relieve que la incidencia de los debates sobre la guerra se convirtieron en uno de los ejes sobre los cuales se movió la política local, incluso en poblaciones pequeñas y aparentemente ajenas al conflicto. De esta manera, se apunta como conclusión general la necesidad de revisar las interpretaciones que han planteado que los debates intelectuales solamente afectaron a círculos reducidos en España.

Palabras clave: Primera Guerra Mundial; intelectuales; sociedad; política; estudios locales.
Abstract: This article analyzes the political and social impact of the well-known controversies between aliadófilos and germanòfilos that dominated Spain during World War I. In addition to studying the links between intellectual approaches and the various political groups in large cities, it focuses on a case study, the Catalan province Gerona, to highlight that the impact of debates about the war became one the axes on which local politics were developed, even in small towns, seemingly distant from the conflict. The general conclusion points to the need to review the interpretations which have argued that intellectual debates only affected small circles in Spain between 1914 and 1918.

Key Words First World War, intellectuals, society, politics, local studies.. 


\section{LA GRAN GUERRA EN ESPAÑA: POLÉMICAS INTELECTUALES E IMPACTO POLÍTICO Y SOCIAL ${ }^{1}$}

\section{INTRODUCCIÓN}

Al calor del centenario de la Gran Guerra que actualmente seguimos conmemorando, una importante cantidad de obras de desigual calidad e impacto historiográfico y mediático han visto la luz ${ }^{2}$. En relación con nuestro país, a pesar de contar con unos relativamente escasos precedentes historiográficos, algunos trabajos han mostrado notables avances y han dejado al descubierto el gran campo que nos queda por recorrer para aproximarnos a una visión global del impacto del conflicto nivel local y a las múltiples relaciones entre lo que aconteció aquí y en el resto del mundo ${ }^{3}$. En este contexto, a pesar de que estamos lejos de asistir a verdaderos debates, el análisis del impacto social o popular de los debates intelectuales sobre los diversos posicionamientos asumidos frente al dilema provocado por a la guerra, la tan manida disputa entre aliadófilos y germanófilos, ha suscitado opiniones divergentes entre los especialistas. Lo resumía Javier Moreno Luzón en un texto donde reseñaba algunos de los libros más relevantes publicados con motivo del centenario: "no hay acuerdo entre los especialistas

\footnotetext{
1 Este trabajo forma parte del proyecto HAR2016-75324-P, La patria hispana, la raza latina. Intelectuales, identidades colectivas y proyectos políticos entre España, Italia y Argentina (1880-1945).

${ }^{2}$ Probablemente sea necesario apuntar, por lo que tiene que de estado de la cuestión, los tres volúmenes de la monumental Jay WINTER (ed.), Cambridge History of the First World War, Cambrigde, Cambridge University Press, 2014.

${ }^{3}$ Seguramente los libros más relevantes que se publicaron en los últimos años son los siguientes: Fernando GARCÍA SANZ, España en la Gran Guerra. Espías, diplomáticos y traficantes, Barcelona, Galaxia Gutenberg, 2014; Eduardo GONZÁLEZ CALLEJA y Paul AUBERT, Nidos de espías. España, Francia y la Primera Guerra Mundial (19141919), Madrid, Alianza, 2014; Maximiliano FUENTES CODERA, España en la Primera Guerra Mundial. Una movilización cultural, Madrid, Akal, 2014. Todos ellos han continuado el trabajo fundamental de Francisco ROMERO SALVADÓ, España 1914-1918. Entre la guerra y la revolución, Barcelona, Crítica, 2002. Sobre las relaciones del caso español con otros países neutrales, véanse Xavier PLA, Maximiliano FUENTES CODERA y Francesc MONTERO (eds.), A Civil War of Words. The Cultural Impact of the Great War in Catalonia, Spain, Europe and a glance at Latin America, Oxford, Peter Lang, 2016; José-Leonardo RUIZ SÁNCHEZ, Inmaculada CORDERO OLIVERIO y Carolina GARCÍA SANZ (eds.), Shaping Neutrality throughout the First World War, Sevilla, Universidad de Sevilla, 2016; Johan DEN HERTOG y Samuël KRUIZINGA (ed.), Caught in the Middle: Neutrals, Neutrality and the First World War, Amsterdam, Aksant, 2011 y los artículos de Carolina García Sanz y Javier Ponce en 1914-1918 Online. International Encyclopedia of the First World War (disponible en http://encyclopedia.1914-1918online.net/home; consultada el 12 de mayo de 2016).
} 
acerca de la penetración en la sociedad española de las preocupaciones por la Gran Guerra"4 . Mientras que algunos autores han defendido la tesis del desarrollo de una "guerra civil de palabras" para ilustrar el impacto de los debates en el seno de la sociedad española ${ }^{5}$, otros, esgrimiendo entre otros argumentos los elevados índices de analfabetismo de la España de entonces, han planteado recientemente que las polémicas entre aliadófilos y germanófilos afectaron "sólo a sectores muy minoritarios" ${ }^{\prime 6}$ y que estos debates solo preocuparon al "segmento de la intelligentsia" y no a "los sectores populares" ${ }^{7}$.

Como ha mostrado Michael Neiberg, los parámetros culturales fueron un elemento central en el proceso por el cual una parte significativa de las sociedades europeas asumió que sus respectivos países no habían sido los causantes del estallido del conflicto y que, en consecuencia, su participación en él se debía únicamente a una respuesta defensiva frente al enemigo ${ }^{8}$. En este marco, los intelectuales formaron parte de un engranaje mucho más amplio que dio lugar a un proceso de movilización cultural en todos los países. No por casualidad Christophe Prochasson ha llegado a referirse a ellos como el “tercer frente" ${ }^{\prime 9}$. La guerra les convirtió, en su mayoría, en una pieza fundamental para la actualización de unos discursos sobre la nación que incorporaron con fuerza y radicalidad la idea estereotipada del enemigo como pieza medular de las "culturas de guerra" ${ }^{10}$. A pesar de que no se produjo sin tensiones y fisuras ${ }^{11}$, este proceso les situó en una primera línea en la producción y reproducción de las imágenes del enemigo y las propias identidades nacionales de guerra y les llevó a establecer una relación estrecha con los poderes políticos y militares. Las intensidades de los procesos que tuvieron lugar en los países neutrales fueron, por obvias razones, de una intensidad sensiblemente menor a la de los territorios beligerantes. Sin embargo, no obstante la neutralidad, experimentaron procesos similares. Las líneas por las que se movieron los apasionados debates en Italia o Portugal sobre el intervencionismo y la

4 Javier MORENO LUZÓN, “Una guerra no declarada", Revista de Libros, 23 de febrero de 2015 (disponible en
http://www.revistadelibros.com/articulo imprimible.php?art=742\&t=blogs, consultado el 7 de mayo de 2016).

5 Gerald MEAKER, "A Civil War of Words: The Ideological Impact of the First World War on Spain, 1914-1918", Hans SCHMITT (ed.), Neutral Europe Between War and Revolution, 1917-1923. Charlottesville, The University Press of Virginia, 1988, pp. 1-65. Siguen esta línea, aunque con algunos matices, Maximiliano FUENTES CODERA, España en la Primera Guerra Mundial..., op. cit. y Eduardo GONZÁLEZ CALLEJA y Paul AUBERT, Nidos de espías..., op. cit.

${ }^{6}$ Fernando GARCÍA SANZ, España en la Gran Guerra...., op. cit., p. 45.

7 Joan ESCULIES, “España y la Gran Guerra: nuevas aportaciones historiográficas”. Historia y Política, no 32 (2014), p. 58.

${ }^{8}$ Michael NEIBERG, Dance of the furies. Europe and the outbreak of World War I, Cambridge, Harvard University Press, 2011.

${ }^{9}$ Christophe PROCHASSON, 14-18. Retours d'expériences, París, Tallandier, 2008.

${ }^{10}$ Sobre el concepto "cultura de guerra" y los debates que provocó su utilización en la historiografía, véase un resumen en Leonard SMITH, "The Culture de guerre and French Historiography of the Great War of 1914-1918", History Compass, no 5-6 (2007), pp. 1967-1979 y, más recientemente, Hervé MAZUEL, “Un tournant historiographique: I'histoire culturelle de la Grande Guerre", Philippe POIRRIER (dir.), La Grande Guerre. Une histoire culturelle, Dijon, Éditions Universitaires de Dijon, 2015, pp. 19-40.

${ }^{11}$ Véanse en este sentido, los siguientes trabajos: Nicolas, MARIOT Tous unnis dans la tranchée? 1914-1918, les intellectuels rencontrent le peuple, París, Seuil, 2013 (para el caso francés) y Roger CHIKERING, “'War Enthusiasm?'. Public Opinion and the Outbreak of War in 1914", Holger AFFLERBACH y David STEVENSON (eds.), An Improbable War: the outbreak of World War I and European political culture before 1914, Nueva York y Oxford, Berghahn Books, 2007, pp. 200-212 (para el caso alemán). 
neutralidad durante los primeros meses del conflicto no estuvieron lejos de las que conocemos bien para los casos de Francia o Alemania ${ }^{12}$. Elementos similares pueden observarse en los países escandinavos o los Países Bajos ${ }^{13}$. Lo propio sucedió con muchos países de América Latina, entre los cuales, como muestran los casos de Argentina y Brasil, los apasionados debates sobre la neutralidad o la intervención -las disputas entre aliadófilos y germanófilos- no solamente se desarrollaron a partir de unos tópicos similares a los conocidos en los principales países europeos, sino que también fueron vividos de manera apasionada en las calles ${ }^{14}$. En este contexto, el caso español resulta muy poco excepcional.

Los casos de los países neutrales, y el español entre ellos, ofrecen la posibilidad de analizar la relación que se estableció entre tres elementos que, por muchos motivos -entre ellos, la censura y la presión ejercida sobre la disidencia-, son más complejos de observar con nitidez en las potencias beligerantes: la relación establecida entre los posicionamientos intelectuales sobre la guerra, los discursos sobre la nación y los proyectos políticos en pugna. Estos tres elementos, a su vez, ejercieron una destacada influencia en las diferentes sociedades y sus colectivos. Partiendo de este marco general y siguiendo una perspectiva recientemente apuntada por Nicolas Mariot, este artículo intenta profundizar en una línea de trabajo poco desarrollada hasta ahora. No busca realizar un nuevo análisis sobre el compromiso de los intelectuales para ver cómo "la guerre a tranformé leur activité" ${ }^{15}$ sino que, sin olvidar esto elemento, pretende aproximarse al estudio del impacto social y cultural de sus posicionamientos $-\mathrm{y}$ los debates que estos promovieron- frente al conflicto a través de algunos ejemplos puntuales surgidos de diversas fuentes poco exploradas y, sobre todo, del análisis de un caso regional. Partiendo de este objetivo general, se pondrá el foco en los debates desarrollados entre 1914 y 1918 , los alineamientos y los espacios de sociabilidad intelectual y sus relaciones con la política a nivel estatal y regional para analizar tanto los discursos sobre las naciones -la española y la catalana en particular- como la influencia social y política de las áridas polémicas que de ellos se derivaron.

\section{DOS CAMPOS ENFRENTADOS}

Es bien conocido: frente al inicio de las hostilidades en Europa, el gabinete de Eduardo Dato, con el acuerdo de Alfonso XIII, se apresuró a declarar la neutralidad. No es éste el lugar donde entrar en

\footnotetext{
12 Patrizia DOGLIANI, "A Civil War of Words in Italy: Italian Intellectuals from Interventionism into WWI to Engagement into Fascism" y Ana Paula PIRES, "The Sound of the Mind: Portugueses Intellectuals and the First World War", Xavier PLA, Maximiliano FUENTES CODERA y Francesc MONTERO (eds.), A Civil War of Words..., op.cit., pp. 55-98.

${ }^{13}$ Véanse Erik BAZIER, "Norway and the First World War: The Search for a Norwegian Identity in the Trenches, 1914-1918" y Bjarne S. BENDTSEN, "Scandinavian Interpretations of the First World War as a European Civil War", José-Leonardo RUIZ SÁNCHEZ, Inmaculada CORDERO OLIVERIO y Carolina GARCÍA SANZ (eds.), Shaping Neutrality..., op. cit., pp. 361-377 y 401-421, y Claes AHLUND (ed.), Scandinavia in the First World War, Lund, Nordic Academic Press, 2012. Sobre los Países Bajos: Maartje ABBENHUIS, The Art of Staying Neutral. The Netherlands in the First World War, 1914-1918, Amsterdam, Amsterdam University Press, 2006.

14 Olivier COMPAGNON, América Latina y la Gran Guerra. El adiós a Europa (Argentina y Brasil, 1914-1939), Buenos Aires, Crítica, 2014.

${ }^{15}$ Nicolas MARIOT, "Repos du guerrier et loisirs populairs: que nous disent de la culture de guerre les pratiques culturelles des poilus", en Philippe POIRRIER (dir.), La Grande Guerre. Une histoire culturelle, Dijon, Éditions Universitaires de Dijon, 2015, p. 43.
} 
los detalles que le llevaron a tomar esta decisión, pero basta mencionar la debilidad y falta de preparación del Ejército y la también débil posición de España en relación con las potencias europeas ${ }^{16}$. Durante los primeros meses, a pesar de algunas declaraciones ciertamente disonantes pronunciadas desde diferentes perspectivas y motivaciones por Alejandro Lerroux, Melquíades Álvarez y el conde de Romanones, la neutralidad estuvo lejos de estar cuestionada. No solamente los partidos dinásticos sostuvieron la posición oficial, sino que incluso sectores republicanos y el Partido Socialista no dudaron en plantear que no debía cuestionarse la neutralidad ${ }^{17}$. Personajes de la izquierda republicana y catalanista como Francesc Layret llegaron a afirmar que lo mejor era "afirmarse en obligar al gobierno a mantener la neutralidad cueste lo que cueste" ${ }^{18}$. No obstante, esta poco cuestionada posición oficial dio pasó a una situación muchísimo más compleja. Pronto la neutralidad no fue otra cosa que una imposición que los periódicos y los intelectuales intentaron eludir siempre que pudieron para manifestar sus posiciones.

Con cierta rapidez, la gran mayoría de las publicaciones se llenaron de opiniones e informaciones sobre la guerra. "Es difícil sustraerse hoy a la pesadilla de la guerra (...) Pensar hoy en otra cosa que en la catástrofe apocalíptica, es casi sacrílega ligereza", afirmaba la prensa gerundense pocos días después del inicio de las movilizaciones en Europa ${ }^{19}$. Algo parecido sucedía en el conjunto del país. Durante las semanas posteriores comenzó a observarse que la sociedad española empezaba a dividirse en dos campos abiertamente enfrentados que, no obstante, en su interior albergaban grupos, individuos e intereses políticos y culturales no siempre convergentes. Aliadófilos y germanófilos -así se conocieron dichos campos popularmente- mostraron que los posicionamientos sobre la guerra estaban directamente relacionados con unos proyectos políticos y nacionales concretos. Por ello, no resulta extraño que durante estas primeras semanas -siempre sin cuestionar la neutralidad- periódicos carlistas locales como El Norte de Gerona afirmaran que Alemania, cuyo Estado Mayor había realizado "prodigios de cálculo y organización, que pronto serán el asombro del mundo" no tendría problemas en vencer a una Francia "en pleno desgobierno y desorientación" ${ }^{20}$. Tampoco resulta extraño que desde periódicos católicos, en este caso de Madrid, se afirmara la guerra podía ser "un instrumento de la justicia y la misericordia" contra "naciones prevaricadoras" como Inglaterra y Francia ${ }^{21}$. Seguramente, quien mejor ejemplificó esta situación fue Antoni Fabra i Ribas, socialista y ferviente aliadófilo, en la conclusión de un libro publicado en 1915: "como españoles debemos ser fervientes partidarios de la no intervención armada en el conflicto europeo (...) Ahora bien; la no intervención armada y la neutralidad

\footnotetext{
${ }^{16}$ Francisco ROMERO SALVADÓ, España 1914-1918..., op. cit., p. 7; Fernando GARCíA SANZ, España en la Gran Guerra...., op. cit., pp. 27-35; Nuño AGUIRRE DE CÁRCER, La neutralidad de España durante la Primera Guerra Mundial, Madrid, Ministerio de Asuntos Exteriores, 1995; Javier PONCE MARRERO, "La política exterior española de 1907 a 1920: entre el regeneracionismo de intenciones y la neutralidad condicionada", Historia Contemporánea, no 34 (2007), pp. 93-116.

${ }^{17}$ Maximiliano FUENTES CODERA, España en la Primera Guerra Mundial..., op. cit., pp. 41-51.

${ }^{18}$ El Poble Català, 3 de agosto de 1914, p. 1.

${ }^{19}$ S. A., “La visión de la Guerra”, El Norte, 6 d'agost de 1914, p. 1.

${ }^{20}$ Cirici VENTALLÓ, “Las diferencias entre Francia y Alemania”, El Norte, 7 d'agost de 1914, p. 1.

21 “Impresiones", El Siglo Futuro, 8 de agosto de 1914, p. 1.
} 
oficial, no puede ni debe impedir que contribuyamos moral y materialmente, en la medida de lo que podamos, a la derrota del kaiserismo" ${ }^{22}$.

El problema, en realidad, no era la neutralidad sino los argumentos que la sostenían. Por ello, rápidamente dejó de hablarse de neutralidad y pasó a hablarse de neutralidades con diversas adjetivaciones -activas, benévolas, críticas- que denotaban unas preferencias políticas concretas. Esquemáticamente, entre los simpatizantes de las potencias centrales destacaron la Corte -con la notable excepción de Alfonso $\mathrm{XIII}^{23}$ - y el conjunto de la aristocracia, liderados por María Cristina, las altas jerarquías del Ejército, la mayoría de la Iglesia católica y los partidos carlista y maurista. Entre los partidarios de los aliados resaltaron los diversos agrupamientos republicanos, los partidos socialista y reformista, y la mayoría de los intelectuales. Esta ya algo tópica división, no obstante, no debe ocultar las numerosas excepciones existentes dentro de cada grupo y la presencia de algunos pocos casos de trasvases entre estos dos bloques. Entre las excepciones, cabe destacar los casos de Melchor Ferrer, secretario personal del aliadófilo pretendiente Jaime III, del también carlista Franciso Melgar, de sectores del Ejército o de la Iglesia favorables a la causa aliada, y en la segunda tipología resalta sin duda el itinerario de Luis Antón de Olmet ${ }^{24}$.

En este marco, los sectores aliadófilos se apresuraron por vincular la guerra a la política española. No es que los germanófilos no lo hicieran. Vázquez de Mella, uno de sus más destacados líderes, lo demostró sobradamente desde el inicio del conflicto ${ }^{25}$. Sin embargo, los más interesados en que los debates sobre la guerra se extendieran al conjunto del país y llegaran a influir sobre la sociedad fueron los partidarios de los aliados y en particular los francófilos. Por ello, la Junta Nacional del Partido Reformista reunida el 20 de octubre de 1914 afirmó que a pesar de que España no podía ni debía "en modo alguno quebrantar su neutralidad", ésta no podía ser una manifestación de "inercia, sino todo lo contrario". Neutralidad no podía ser sinónimo de indiferencia: se había de luchar contra la "peligrosa inconsciencia" que pretendía imponer el gobierno conservador, se debía emprender "una campaña patriótica en sentido nacional y liberal, removiendo el espíritu público y procurando en lo posible, mediante una labor intensa de reconstitución política y social, preparada con la inminencia que el caso requiere, para la misión que debe realizar en el presente y en el porvenir" ${ }^{26}$. En cierta manera, la reformista fue una perspectiva compartida con socialistas y diversos núcleos catalanistas republicanos.

\footnotetext{
${ }^{22}$ Antoni FABRA I RIBAS, El socialismo y el conflicto europeo, Valencia, Prometeo, s/f, p. 247.

${ }^{23}$ Antonio NIÑO, "El rey embajador. Alfonso XIII en la política internacional”, Javier MORENO LUZÓN (ed.), Alfonso XIII. Un político en el trono, Madrid, Marcial Pons, 2003, pp. 254-261.

${ }^{24}$ Sobre los carlistas, Jordi Canal, El carlismo. Dos siglos de contrarrevolución en España, Madrid, Alianza, 2000, pp. 269- 271 y Maximiliano FUENTES CODERA, España en la Primera Guerra Mundial..., op. cit., pp. 70-71; sobre los sectores del Ejército, Gerald MEAKER, "A Civil War of Words...", op. cit., p. 56; sobre la Iglesia, Alfonso BOTTI, "Chiesa e cattolici spagnoli di fronte alla Grande Guerra: un sondaggio", Dimensioni e problemi della ricerca storica, no 1 (2015), pp. 110-129); sobre el caso de Luis Antón de Olmet, Maximiliano FUENTES CODERA, España en la Primera Guerra Mundial..., op. cit., p. 110.

${ }^{25}$ Maximiliano FUENTES CODERA, “Germanófilos y neutralistas: proyectos tradicionalistas y regeneracionistas para España (1914-1918)», Ayer, no 91 (2013), pp. 63-92.

26 "El Partido Reformista. Nota oficiosa”, El Liberal, 20 de octubre de 1914, p. 3. La referencia a este artículo ha sido extraída de Santos JULIÁ, "La nueva generación: de neutrales a antigermanófilos pasando por aliadófilos", Ayer, $\mathrm{n}$ 우 93, 2013, pp. 131-132.
} 
Todos ellos sostuvieron prácticamente los mismos argumentos en estos momentos iniciales del conflicto y lo interpretaron como una disputa entre la autocracia germana y las democracias francesa e inglesa, como una lucha entre naciones e imperios que debía marcar el futuro del país. Estos argumentos sobre la neutralidad, vale la pena tenerlo presente, no solamente se detectaban en Madrid - Barcelona, también aparecían, a menudo adaptados al mundo local correspondiente en periódicos provinciales y comarcales ${ }^{27}$. Los matices existían y se profundizarían en los años posteriores, pero el punto de partida era compartido.

En este escenario, los intelectuales pronto ocuparon un espacio de relevancia y contribuyeron decisivamente en el desarrollo de las argumentaciones sobre la neutralidad. Agosto de 1914 les encontró sumidos en un proceso de renovación general liderado por el Ortega de "Vieja y Nueva Política" que no supuso, sin embargo, una ruptura total con la generación precedente ${ }^{28}$. La guerra apareció como un momento de ruptura, casi de fundación -e incluso de purificación espiritual para algunos de ellos-, y pasó a ocupar casi exclusivamente el centro de sus preocupaciones: "Lo único de veras importante e interesante que ahora ocurre, es la Guerra Europea y sus consecuencias, directas e indirectas, de todo orden. Junto a ello, todo otro asunto carece de verdadero valor", escribió Miguel de Unamuno en Nuevo Mundo el 12 de setiembre. A pesar de que Ortega le prestó una escasa atención al tema durante las primeras semanas de guerra, advirtió que mientras comenzaba "el incendio del mundo", "una edad suculenta y fertilísima para lo esencialmente humano", Madrid parecía aletargada, "muy próxima a la idiotez" ${ }^{29}$. En realidad, Ortega estaba haciendo suya una percepción muy parecida a la que habían planteado con acentos diversos todos los sectores aliadófilos y que el mallorquín Gabriel Alomar había resumido con clarividencia: "El sujeto de la neutralidad no es la nación, sino el Estado" ${ }^{30}$. De lo que se trataba, pues, era de regenerar la nación. Una vez más. Desde esta perspectiva, la gran mayoría de los intelectuales que habían bebido de las fuentes del regeneracionismo y el institucionismo recondujeron sus ideas en el marco de un heterogéneo aliadofilismo, radicalizando sus argumentaciones a la espera de que la influencia de Europa, primero en guerra y después en paz, sacara a España de su decaimiento nacional.

El problema era que estos intelectuales aliadófilos no estaban solos en esta lucha por la nación. Tal como sucedió en el conjunto del continente, la división se escenificó en una serie de manifiestos. El primer texto que apareció fue el neutralista y europeísta "Manifest del Comitè d'Amics de la Unitat Moral d'Europa" redactado por Eugenio d'Ors y hecho público a finales de noviembre de 1914 en

\footnotetext{
27 Para el caso de las comarcas gerundenses, véase Maximiliano FUENTES CODERA, La Gran Guerra a les comarques gironines. L'impacte cultural i polític, Girona, Diputació de Girona, 2015, pp. 37-47.

28 Manuel Menéndez Alzamora, La Generación del 14. Una aventura intelectual, Madrid, Siglo XXI, 2006, pp. 232-261.

29 “Anotaciones sobre la guerra en forma de diario", en José ORTEGA Y GASSET, Obras completes. Tomo X. Escritos políticos - I (1908-1921), Madrid, Revista de Occidente, 1969, pp. 250-255. Sobre Ortega durante la guerra, véase Ferran ARCHILÉS, "Una nación descamisada. Ortega y Gasset y su idea de España durante la Primera Guerra Mundial (1914-1918)", Rúbrica Contemporánea, o 8 (2015), disponible en http://revistes.uab.cat/rubrica/article/view/v4n8-archiles/pdf 5.
}

${ }^{30}$ Gabriel ALOMAR, “Entorn del neutralisme”, La Campana de Gracia, 3 de octubre de 1914, p. 3. 
Barcelona $^{31}$. Como respuesta a esta iniciativa, un numeroso grupo de intelectuales catalanes, en su mayoría vinculados a sectores nacionalistas republicanos, firmó el "Manifest dels Catalans", una clara demostración de la francofilia dominante en el catalanismo que apareció el 26 de marzo de 1915. Bajo la dirección de Ortega, un importante número de hombres de letras vinculados en su mayoría -aunque no exclusivamente- al Ateneo de Madrid, el reformismo y el republicanismo lanzaron España el 29 de enero de 1915. Fue allí donde vio la luz el 9 de julio el "Manifiesto de adhesión a la naciones aliadas", redactado por Ramón Pérez de Ayala con el propósito de que España dejara de parecer "una nación sin eco en las entrañas del mundo". Finalmente, el sector germanófilo hizo evidente su presencia como colectivo con un manifiesto de Jacinto Benavente -“Amistad hispano-germana" fue su título- publicado en el maurista La Tribuna el 18 de diciembre de $1915^{32}$.

El debate sobre aliadófilos y germanófilos había dejado de ser nada más que una polémica sobre los valores culturales, científicos o filosóficos de Alemania, Francia o Inglaterra. "Todo el mundo dice que la opinión española se encuentra dividida frente al conflicto europeo en relación con sus afinidades políticas", había escrito el hispanista Albert Mousset en abril ${ }^{33}$. De hecho, no fue fácil para Dato cumplir con la declaración de neutralidad en todos sus términos. A pesar de que las Cortes se había clausurado en febrero y que la proyección de una guerra breve se había desvanecido, se había vuelto cada vez más difícil determinar cuándo la libre expresión de las preferencias derivaba en exaltación de alguno de los contendientes. La guerra no solamente se había convertido en unos de los ejes centrales del debate intelectual, también había devenido una fuente de enfrentamientos sociales. Tal como recoge el Diario de Sesiones de las Cortes de los primeros meses de 1915, una representación del Lohengrin de Wagner en el Liceo de Barcelona podía originar una sonora pitada de los aliadófilos para después convertirse en una batalla campal, o una misa en La Coruña podía acabar convertida en un mitin germanófilo si el párroco recordaba los muertos en el frente. La crispación fue tal que llegaron a suspenderse las funciones de teatro que pudieran alterar el orden y se prohibió la proyección de películas y noticiarios en los que se hiciera referencia a las potencias en guerra ${ }^{34}$. El debate se había desparramado por el conjunto del país, desde Galicia al País Vasco pasando por las Islas Canarias ${ }^{35}$.

Cataluña tampoco había permanecido ajena a esta situación ${ }^{36}$. Algunas de sus poblaciones vivieron estos meses con gran intensidad. En Girona, entonces una ciudad de unos 16.000 habitantes, la

\footnotetext{
${ }^{31}$ Maximiliano FUENTES CODERA, El campo de fuerzas europeo en Cataluña. Eugeni d'Ors en los primeros años de la Gran Guerra, Lérida, Universitat de Lleida - Pagès Editors, 2009.
}

32 Santos JULIÁ, Nosotros, los abajos firmantes. Una historia de España a través de manifiestos y protestas (1896-2013), Madrid, Galaxia Gutenberg, 2014, pp. 20-24. Los textos pueden consultarse en este mismo volumen.

\footnotetext{
33 Albert MOUSSET, “L’Espagne dans le conflit actuel”, La Grande Revue, abril de 1915, p. 192.
}

${ }^{34}$ Maximiliano FUENTES CODERA, España en la Primera Guerra Mundial..., op. cit., pp. 62-63.

${ }^{35}$ A modo de ejemplo, véanse Mercedes ROMÁN PORTAS, “Aliadofilia y neutralidad de 'La Voz de Galicia' en los años de la Primera Guerra Mundial”, Historia y Comunicación Social, 18, 2013, pp. 293-303; Andreu NAVARRA ORDOÑO, 1914. Aliadófilos y germanófilos en la cultura española, Madrid, Cátedra, 2014, pp. 193-200; Javier PONCE MARRERO, "Prensa y germanofilia en Las Palmas durante la Gran Guerra", Anuario de Estudios Atlánticos, 38, 1992, pp. 581-602; Manuel MARTíNEZ HERMOSO, La Primera Guerra Mundial en la prensa sevillana (19141918), Sevilla, Padilla Libros, 1998.

${ }^{36}$ Para el caso catalán, véanse David MARTíNEZ FIOL (ed.), El catalanisme i la Gran Guerra. Antologia, Barcelona, La Magrana, 1988 y, de más reciente factura, Joan ESCULIES y David MARTíNEZ FIOL, 12.000! Els catalans a la 
neutralidad llegó a ser también sinónimo de defensa de los valores expresados por los soldados alemanes, cuyo "estoicismo", desde el punto de vista de los sectores regionalistas locales, podía ser un modelo para España: "Cuán bueno sería que inculcásemos a las nuevas generaciones el amor a nuestras glorias, el culto a la disciplina, la aceptación previa de los sacrificios que la Patria un día pudiera exigir!... Y sobre todo, icuán bueno sería fortalecer las almas jóvenes, dándoles por norte de su vida un alto y noble ideal!" ${ }^{37}$. Mientras tanto, en la población costera de Sant Feliu de Guíxols se contestaba con dureza a los argumentos de los "católicos, apostólicos y romanos", "los más rabiosos partidarios y los más desenfrenados defensores de Alemania y Austria" ${ }^{38}$. Estas disputas no era excepcionales en las comarcas gerundenses, donde podían leerse artículos que, como los de Unamuno y Araquistáin, advertían sobre la división entre germanófilos y aliadófilos como una expresión de la "nuestras guerras civiles" ${ }^{39}$. También podían leerse reproducciones y adaptaciones de discursos y artículos que defendían posiciones próximas al carlismo ${ }^{40}$. La importancia concedida al conflicto asumió una relevancia notable. Un periódico republicano catalanista de Sant Feliu de Guíxols -una población que entonces contaba entonces con unos 11.000 habitantes y que, por su orientación hacia la industria del corcho, resultó fuertemente afectada por la guerra- llegó a publicar en setiembre de 1915 un artículo donde analizó de manera programática los bandos en disputa. Su posición, como la del conjunto del republicanismo catalanista, mostró que la división en dos bandos se reproducía también, aún de manera incipiente, en el mundo local: "Los dos caminos se separan en un mismo punto. Y la elección no puede ser dudosa si se arrancan las vendas que cubren los ojos. La neutralidad a gritos no es otra cosa que una careta de la guerra" $^{41}$.

En este marco, los intelectuales de las ciudades pequeñas y medianas ocuparon un lugar central en la circulación y adaptación de los argumentos que dominaban los debates europeos y españoles. Estos "intermediarios culturales", entre los cuales no pueden olvidarse los maestros y profesores, fueron centrales para que el conflicto y sobre todo los posicionamientos alrededor de él se convirtieran en uno de los ejes centrales de la política local. Como recordaba una publicación dirigida a los maestros gerundenses, era fundamental prepararse para "formar una juventud sincera" y "henchida de ideales" porque una vez finalizado el conflicto "la vida mundial presentará nuevas modalidades que trascenderán el campo de la educación” ${ }^{42}$.

En este sentido, en las comarcas gerundenses destacó una efímera revista publicada en la ciudad Girona con el título de Cultura, que se publicó entre setiembre de 1914 y febrero del año siguiente $^{43}$. Allí se conjugaron artículos sobre literatura francesa e italiana con textos sobre las "dos

Gran Guerra, Barcelona, Ara Llibres, 2014.

37 “Las enseñanzas de la guerra”, Diario de Gerona, 6 de mayo de 1915, pp. 2-3.

38 "Contrastes e incongruencias", El Programa, 26 de junio de 1915, p. 1.

39 Juan GUIXÉ, “Los acontecimientos de mañana. El día de la paz”, El Autonomista, 24 de octubre de 1915, p. 1.

${ }^{40}$ Como ejemplos, “La libre (¿) Francia. ¿Hasta cuándo?”, El Norte, 14 de enero de 1915, p. 1; PLINIO, “Nota del día", El Norte, 27 de julio de 1915, p. 1.

41 “España ante el conflicto europeo”, El Programa, 23 de setiembre de 1915, p. 1.

42 “Actualidad”, El Magisterio Gerundense, 2 de setiembre de 1914, pp. 1-4.

${ }^{43}$ Cultura. Revista Mesal. Edición facsímil con estudio introductorio de Maximiliano FUENTES CODERA, Girona, Edicions de la Ela Geminada, 2014. 
Alemanias" -firmado por Carles Rahola-, un tópico recurrente entre los intelectuales europeos, la "barbarie" germana -obra de Prudenci Bertrana- y traducciones de artículos de Ernest Renan y Maurice Maeterlinck. Todo se combinaba, a su vez, con una notable presencia del componente latinista que permitía a la revista relacionar catalanismo con aliadofilia y abría la puerta a la defensa de los "voluntarios" catalanes que participaban en el ejército francés ${ }^{44}$. El papel de personajes como Carles Rahola y Josep Puig Pujades en periódicos como El Autonomista o Empordà Federal fue fundamental para traducir los debates europeos entre las poblaciones locales y convertir un debate de ideas en una disputa sobre la política interna. Así se expresó, por ejemplo, en la edición de un número de homenaje a Bélgica publicado en el diario del republicanismo de Figueres en abril de 1915 que, no casualmente, apareció el mismo día que la revista insignia de la aliadofilia catalanista, Iberia, lanzaba su primer número con el propósito de reafirmar los valores de democracia, libertad y respeto a "todas las nacionalidades". Las antinomias sobre los "bárbaros" alemanes que habían atacado una Bélgica neutral -un elemento central de la propaganda aliada en los países neutrales y beligerantes ${ }^{45}$ - donde "todo era paz y bonhomía" encabezaban un ejemplar donde aparecían desde referencias al "Libro gris" belga hasta textos de Pere Coromines -sobre la "Bélgica latina"-, Francesc Layret, Puig Pujades, Carles Rahola y los diputados republicanos Joaquim Salvatella y Salvador Albert. La vinculación entre neutralidad, germanofilia y abulia nacional aparecía con toda evidencia y el periódico llegó a plantearse comparando la guerra europea con la presencia española en el norte de África- si no "se daría la sangre y el dinero, con más gusto, con más provecho, para retornar la libertad a los belgas que para quitársela a los moros" ${ }^{46}$.

El debate sobre la guerra dejó de ser ya una cuestión meramente intelectual o un entretenimiento para el mundo de la cultura y llegó a impregnar los argumentos de las fuerzas electorales que se enfrentaron en los comicios municipales de noviembre de 1915. El Autonomista, el principal periódico del republicanismo catalanista de Girona e impulsor de una candidatura liberal republicana, no dudó en afirmar se enfrentaban a "los enemigos de la libertad, llámense como se llamen, que el nombre no importa si son todos iguales, carlistas, regionalistas, conservadores de toda laya" ${ }^{\prime 7}$. Como todos ellos eran germanófilos, no era extraño que unos días después llegara a afirmarse que "Si triunfara Alemania, caería la humanidad en una noche de tiranía y de despotismo. Si triunfan Inglaterra y Francia, abríranse los pueblos, caminos de libertad que harán florecer las más bellas esperanzas" ${ }^{\prime 8}$. Las conexiones entre las elecciones locales y la guerra eran tan evidentes para los lectores como la vinculación establecida entre los postulados federalistas -era habitual encontrar reproducciones de textos de $\mathrm{Pi}$ i Margall en sus páginas-y el rechazo al imperialismo alemán defendido por las fuerzas conservadoras en España ${ }^{49}$.

44 David MARTíNEZ FIOL, Els "Voluntaris catalans" a la Gran Guerra (1914-1918), Barcelona, Publicacions de l'Abadia de Montserrat, 1991.

${ }^{45}$ Sobre este tema, véase John HORNE y Alan KRAMER, German Atrocitites, 1914: a History of Denial, New Haven, Yale University Press, 2001.

46 J. ROIG, "Espanya i Bélgica", Empordà Federal, 10 de abril de 1915, p. 13.

47 "Nuestra candidatura”, El Autonomista, 14 de noviembre de 1915, p. 1.

${ }^{48}$ José COLL, “Lo que la guerra significa”, El Autonomista, 14 noviembre de 1915, p. 2.

${ }^{49}$ Como ejemplo de estas conexiones, véanse también las referencias a Emilio Castelar en “Alemania y el Kaiser. 


\section{ROMANONES Y LA RADICALIZACIÓN DEL IMPACTO DEL CONFLICTO}

Con la llegada de Romanones al gobierno se intensificó la lucha de argumentos alrededor de la guerra y lo que había comenzado como un debate entre intelectuales devino parte del argumentario político habitual en los círculos políticos y sociales. En las grandes ciudades tuvo un papel especialmente relevante en este proceso la compra o subvención de periódicos, folletos y revistas que las potencias beligerantes realizaron con especial interés y con éxito diverso. El conflicto se convirtió en una guerra de propaganda y, en este marco, países neutrales como España ocuparon un lugar de privilegio para Francia, Alemania o Inglaterra ${ }^{50}$.

Se inició entonces, en diciembre de 1915, un período crucial para comprender la crisis hegemónica del sistema gobernante, que demostró que la cuestión de la neutralidad estaba directamente relacionada con los múltiples conflictos que se desarrollaron internamente. Los rápidos cambios económicos, sociales e ideológicos hicieron evidente que no se podía ocultar por más tiempo la falta de apoyo social y de atractivo popular que padecía el régimen en una época de movilización de masas en el conjunto del continente. A pesar de la favorable acogida del discurso de apertura de las Cortes en mayo de 1916, donde Romanones prometió una pronta resolución de la crisis de subsistencias a través del estímulo de la economía mediante una serie de reformas económicas y financieras, pronto se confirmó la imposibilidad de cumplirlas. Ello condujo a que diferentes grupos sociales -el movimiento obrero, la burguesía industrial catalana y el ejército- recurrieran a soluciones corporativas mediante las cuales consideraron que podían estar mejor protegidos sus intereses particulares. Cuando abandonó el poder en abril de 1917, Romanones dejó un Partido Liberal resquebrajado y un movimiento obrero, una burguesía y un ejército que esperaban ansiosamente el momento de asestar el golpe definitivo al turno dinástico. Con su autoproclamada simpatía por la Entente, la polarización ideológica del país llegó a su punto más álgido. Sin dudas, de todos los presidentes españoles que ejercieron su cargo durante la guerra, Álvaro de Figueroa y Torres fue el que estuvo más implicado en la contienda internacional ${ }^{51}$.

A la altura de 1916 eran ya muchos los que hablaban de un duro enfrentamiento que atravesaba el país. Luis Araquistáin ya había escrito sobre una "guerra civil" el 25 de junio del año anterior en España. Unamuno sentenció el 18 de febrero de 1916 en El Liberal, "en rigor, no hay neutrales. Todos estamos en guerra. No hay más que diferencias de grado". La percepción de una guerra civil latente fue apuntada en repetidas ocasiones en los informes secretos de la diplomacia francesa en Madrid y Barcelona. No sin cierta exageración, en agosto de 1915 ya se había escrito sobre una neutralidad inexistente en la opinión pública española en la que la hostilidad entre germanófilos y aliadófilos era total. Casi un año después, en un largo informe resultante de una misión con el objetivo de aproximar los sectores católicos españoles a Francia encomendada a Jean Gaillard, se destacaba que las discusiones devenían con facilidad "agrias y prolongadas animosidades". La guerra había dividido familias y amigos. En Barcelona, donde esta separación se observó con mayor radicalidad que en otros

\footnotetext{
Una profecía de Castelar", El Autonomista, 16 de febrero de 1916, p. 1.

${ }^{50}$ Eduardo GONZÁLEZ CALLEJA y Paul AUBERT, Nidos de espías..., op. cit., pp. 227-265.

${ }^{51}$ Francisco ROMERO SALVADÓ, España 1914-1918, op. cit., pp. 70-99.
} 
lados, el enviado francés había podido constatar que "aliadófilos y germanófilos, aunque se conocen desde hace mucho tiempo, no se saludan en la calle". En la mayoría de los colegios que había visitado Gaillard en la capital catalana, Zaragoza, Granada, Córdoba, Sevilla, Bilbao, San Sebastián y Madrid había observado que los maestros tenían prohibido a sus alumnos, bajo la amenaza de severas sanciones, los juegos relacionados con la guerra en el patio "porque por lo general este tema conlleva riesgos, y a veces peleas" ${ }^{52}$. La actividad de Gaillard no era en absoluto excepcional. De hecho, Barcelona, Madrid y otras ciudades se convirtieron en campos de acción de auténticas redes de propaganda y espionaje durante estos meses. La estrategia alemana en España se potenció a partir de 1916 y focalizó su actividad en tres grandes objetivos: conseguir el control de la opinión pública, perjudicar los intereses de los aliados y derrocar a cualquier gobierno que fuera hostil a sus intereses, comenzando por el de Romanones. Todos estos objetivos tenían como común denominador una férrea lucha por el mantenimiento de la neutralidad estatal. La propaganda francesa, algo más tardía, y la inglesa, que tuvo un papel destacado en la continuidad de la revista España bajo la dirección de Luis Araquistáin, también destacó tanto en la prensa como en diversas actividades culturales, entre ellas, la visita a Madrid de un comité de intelectuales y científicos franceses encabezado por Henri Bergson en abril de 1916. España y el conjunto de la aliadofilia compartieron esta perspectiva de acercamiento a Francia e interpretaron esta visita como un nuevo episodio en su lucha contra las derechas españolas ${ }^{53}$. Araquistáin se refirió entonces a los intelectuales franceses como "el genio libertador de Francia" e hizo evidente la sintonía entre el semanario y el Ateneo de Madrid y estableció una relación estrecha entre la estimulante visita francesa y la pasiva actitud del gobierno, que, desde su punto de vista, había "hecho lo posible para que estos visitantes pasaran de incógnito". Araquistáin, como Manuel Azaña, exigía que el gobierno abandonara esta política de prescindencia y neutralidad que, mientras Alemania radicalizaba la guerra submarina, contribuía al hundimiento de la nación ${ }^{54}$.

A lo largo de 1916 España se fue convirtiendo en un verdadero punto de encuentro entre la aliadofilia más militante y los sectores socialistas y republicanos de la política y la intelectualidad española, que fueron pasando de mostrar un cierto respeto por las actitudes de Romanones hacia una crítica del conjunto de su gestión. Las simpatías de Araquistáin hacia la política exterior de Romanones no fueron ocultadas, aunque más que en el apoyo al presidente del gobierno sus planteamientos estuvieron centrados en la lucha contra la presión ejercida por las fuerzas germanófilas españolas, a las que culpó del creciente intervencionismo que comenzaba a detectarse entre los partidarios de los aliados $^{55}$. El punto de inflexión de sus planteamientos en relación con la neutralidad llegó con el bloqueo decretado por Alemania y el torpedeo de los mercantes españoles en aguas nacionales por parte de sus submarinos. "La lucha es, no precisamente entre dos Españas, como se ha dicho, sino entre esa España de la susodicha democracia conventual y los españoles que se sienten como tales; es decir,

\footnotetext{
${ }^{52}$ Archivo del Ministère des Affaires Étrangères. Correspondance politique et commerciale. Guerre 1914-1918. Espagne. Vol. 471. Bureau de la Presse Étrangere, "Note sur la presse espagnole", 31 de agosto de 1915; Archivo del Ministère des Affaires Étrangères. Correspondance politique et commerciale. Guerre 1914-1918. Espagne. Vol. 474. Jean Gaillard, “Rapport sur ma mission en Espagne. 3 juin - 13 juillet 1916".

${ }^{53}$ Maximiliano FUENTES CODERA, España en la Primera Guerra Mundial..., op. cit., pp. 135-140.

54 “Aproximación francoespañola”, España, núm. 66, 27-4-1916, pp. 15-16; “Punto de vista”, España, 4 de mayo de 1916, p. 3; “Punto de vista”, España, 11 de mayo de 1916, pp. 3-5.

55 Luis ARAQUISTÁIN, “EI mito intervencionista. Los germanófilos contra Alemania y España”, España, 7 de setiembre de 1916, pp. 3-4.
} 
personas, yos conscientes de una españolidad futura", había escrito Miguel de Unamuno unos meses antes ${ }^{56}$.

En Cataluña, en el contexto de la política de expansión hacia el conjunto de España, el regionalismo y sus intelectuales se habían acercado a una aliadofilia que se relacionaba cada vez más con una crítica a la España restauracionista. Desde el campo del republicanismo catalanista, la francofilia continuaba siendo dominante y daba a Barcelona un carácter mucho más militante que el que podía observarse en Madrid. No solamente Iberia, sino también La Nació, El Poble Català, La Campana de Gràcia y L'Esquella de la Torratxa, entre otras publicaciones, mostraban como la relación entre aliadofilia y republicanismo catalanista podía ser usada tanto para cuestionar las relaciones entre Cataluña y España como para criticar la política neutralista de la Lliga Regionalista. Con estos elementos como trasfondo, no resulta extraño que se observaran puntos de contacto relevantes entre el catalanismo, especialmente el republicano, pero no de manera exclusiva, y las posiciones expresadas en España.

Desde el campo opuesto, los germanófilos se fueron enrocando en la defensa de la más estricta neutralidad. Así lo mostraron sus diversos sectores, desde Juan Vázquez de Mella y el católico Edmundo González Blanco, que rechazaban la política internacional inglesa y los valores republicanos y jacobinos franceses, hasta aquellos que, mostrando unos elementos provenientes del regeneracionismo, pensaban que Alemania, su sociedad, su sistema educativo y su vitalidad nacional debían servir como modelos para proyectar España en una perspectiva modernizadora. Esta simpatía se afirmaba en la defensa de la neutralidad frente al intento de los "farsantes de la cultura, esas hembras del 98" -la cita es de un texto Eloy Luis André en La Esfera del 13 de marzo de 1915- que pretendían que España fuera arrastrada por la guerra. Neutralidad y "españolismo" debían ser compatibles, a diferencia de lo que pretendían imponer los aliadófilos. Así lo mostraron también los intelectuales de la barcelonesa Germania, de la cual fue uno de los colaboradores más activos Faustino Ballvé, quien encabezó la Federación Neutralista Catalana, que continuaba la labor neutralista del marqués de Polavieja (hijo) ${ }^{57}$. Frente a lo que consideraban un intento de hacer que España entrara en la guerra a cualquier coste, no dudaban en sostener un enfrentamiento contra la España "europeizada" pero "desespañolizada del todo", que pretendían imponer Francia y Gran Bretaña y a la cual los intelectuales aliadófilos parecían abrir los brazos con entusiasmo ${ }^{58}$.

La tensión creciente en estos enfrentamientos se observó también en las comarcas gerundenses, donde la crispación dominó la vida cotidiana y la guerra devino un motivo de debate en ciudades y pueblos. No solamente los cines dedicaban sesiones regulares a proyectar noticies sobre los acontecimientos europeos ${ }^{59}$, sino que también era habitual escuchar airadas discusiones entre germanòfils y aliadòfils en las calles principales de poblaciones como Figueres. Algunos aparadores de tiendas llegaron incluso a ornamentarse con motivos bélicos ${ }^{60}$. El debate sobre aliadófilos y

\footnotetext{
${ }^{56}$ Miguel de UNAMUNO, “iEse público...!”, España, 17 de febrero de 1916, pp. 5-6.

57 “Campaña neutralista”, Germania, 1 de marzo de 1917, p. 14. Ballvé fue el responsable de la versión española de Otto HINTZE, Alemania y la guerra, 3 vols., Barcelona, Gustavo Gili, 1916.

58 M. GARCÍA Y PANADÉS, “Evolución hispánica”, Germania, 15 de agosto de 1915, pp. 12-14.

${ }^{59}$ Diario de Gerona, 9 de mayo de 1915.

${ }^{60}$ Anna TEIXIDOR I COLOMER, Amb la República al cap i Catalunya al cor. Empordà Federal 1911-1938, Figueres,
} 
germanófilos llegó a convertirse en parte de la política y ser partidario de Francia e Inglaterra, o de Alemania, implicaba necesariamente asumir unas posiciones concretas en materia de política interna que se expresaban, también, en términos electorales. El impacto social y político de la guerra llegó a estos niveles de profundidad y se expresó, por ejemplo, en las elecciones a Cortes de abril de 1916, donde los regionalistas de Girona -que eran acusados repetidamente de germanófilos por sus posicionamientos conservadores en materia social- se vieron obligados a afirmar que su simpatía por Alemania era solamente una cuestión de "voluntad" y "sentimiento" y que no eran más que neutralistas ${ }^{61}$. Como en el conjunto de España, los sectores republicanos se apresuraron a criticar por partes iguales a carlistas y regionalistas y defendieron su candidato,

"Hombres de libertad: los jaimistas son cómplices de los crímenes cometidos por Alemania contra seres inocentes e indefensos (...) Catalanistas: Cuando Bélgica fue brutalmente invadida por las hordas del kaiser, ¿sabéis quién acusó a los governantes de la nación mártir de haber contraído una gran responsabilidad ante la Historia? Fue La Veu de Catalunya, fué don Francisco Cambó, fueron los inspiradores y los maestros del candidato regionalista. Este es el amor que profesan a la autonomia y a la libertad de los pueblos esos espíritus pequeños que llaman "forastero" al señor Fernández del Pozo. No podéis votar, los que sinceramente hacéis vuestra la causa de las nacionalidades oprimidas (...) No expongáis el distrito a un nuevo predominio de esa gente. Afianzad la democracia y la libertad en el distrito, votando al candidato de todos los republicanos" ${ }^{\prime 62}$.

El impacto de la guerra en la política no solamente se observó en Girona. Lo propio sucedió en Figueres, cuna del republicanismo catalanista, donde Empordà Federal fundamentó la candidatura republicana en nombre de los valores representados por los aliados: los ideales de libertad y federación debían dirigir también las preferencias de los votantes de su ciudad ${ }^{63}$.

\section{LA RADICALIZACIÓN DE LOS POSICIONAMIENTOS Y EL FIN DE LA GUERRA}

Los últimos meses de Romanones mostraron cómo los tempranos posicionamientos de los intelectuales, sus manifiestos y sus círculos de militancia aliadófila y germanófila se habían convertido en posicionamientos políticos sobre el futuro de la nación y sobre el devenir político. La radicalización de este proceso se expresó primero en la fundación de la efímera Liga Antigermanófila, gestada en febrero de 1917 en los salones del Círculo Reformista de Madrid que el gobierno y casi automáticamente prohibida por el gobierno. Como ha planteado Santos Juliá, se esbozó con ella una especie de recomposición de la conjunción republicano-socialista, desaparecida prácticamente en $1912^{64}$. En medio de la inestabilidad política derivada de los problemas de la guerra, la carestía de la vida, y los desafíos obreros y militares, republicanos y socialistas volvíeron a intentar aunar esfuerzos desde los espacios proporcionados por el Ateneo de Madrid y la revista España. Esta liga pretendió expresar en toda su magnitud la estrecha relación establecida entre sus tomas de posición sobre la

\footnotetext{
Ajuntament de Figueres - Diputació de Girona, 2011, p. 64

${ }^{61}$ Jaume BOSACOMA, “Ni germanòfils ni al-liadòfils”, Diario de Gerona, 6 de febrero de 1916, pp. 1-2.

${ }^{62}$ El Autonomista, 5 de abril de 1916, pp. 1-2.

63 "Als electors del Districte de Figueras", Empordà Federal, 6 de abril de 1916, p. 4.

${ }^{64}$ Santos JULIÁ, Vida y tiempo de Manuel Azaña, 1880-1940, Madrid, Santillana, 2010, pp. 146-147.
} 
guerra y la política española. Su texto fundacional destacaba por su radicalidad y por la voluntad de deslegitimar la propaganda germanófila como una expresión de la anti-España. Su manifiesto fundacional, publicado el 18 de enero en España, en pleno debate sobre la nota enviada por Wilson a los países aliados y los ataques alemanes a los barcos españoles, no tenía como objetivo responder a algún otro texto que se hubiera publicado recientemente. Por el contrario, se proponía denunciar la política de neutralidad del gobierno que, como ya habían planteado reiteradamente Araquistáin, Pérez de Ayala y Unamuno, favorecía los intereses alemanes al no responder a los ataques a los barcos españoles. En esta acuciante situación, los partidarios de Alemania pretendían enmascararse bajo un concepto de neutralidad que desfiguraban por completo. La lucha era, pues, no contra los valores o la ciencia alemanes sino contra "los enemigos intestinos de España, a los que se están sirviendo de la terrible tragedia europea para desviar al pueblo español de la única ruta de sus libertades, de sus intereses y de su seguridad internacional" ${ }^{65}$. Era una reedicción de la disputa entre las dos Españas, como se encargó de recordar Unamuno pocos días después ${ }^{66}$.

En la primavera de 1917 el debate sobre la cuestión internacional llegó a su punto culminante. Dos conocidos mítines en Madrid acabaron por demostrar la división de la sociedad española. Exactamente en el mismo recinto y con menos de un mes de diferencia, germanófilos-neutralistas y aliadófilos-intervencionistas reunieron a decenas de miles de personas para mostrar que el país estaba dividido en dos sectores irreconciliables. Diez días después de la caída de Romanones -profundamente presionado por las consecuencias de la guerra submarina alemana y la falta de apoyos internos para llevar adelante una política de contención a los sectores aliadófilos y de la llegada al gobierno del Manuel García Prieto, el 29 de abril, Antonio Maura, que nunca había sido un germanófilo, reunió unas 20.000 personas en un acto anti-aliadófilo en el que se congregaron todos los sectores conservadores. Allí demostró que no pretendía hacer tanto una demostración de simpatía por Alemania como una argumentación en contra de los peligros de que España siguiera los derroteros de Estados Unidos y Rusia $^{67}$. La respuesta de los sectores aliadófilos estuvo precedida por dos manifiestos. En primer lugar, uno del Partido Reformista en el que se afirmaba que después de la abolición de la monarquía en Rusia y de la entrada de Estados Unidos, los demócratas no podían dudar que de un lado estaba la libertad y del otro, la autocracia, "la primera representada por las naciones aliadas; la segunda, por los Imperios Centrales" $^{\prime 68}$. En segunda instancia, otro lanzado por España y dirigido a socialistas y republicanos, que sostuvo que las causas del "lanzamiento" de Romanones estaban directamente vinculadas a la presión de los sectores conservadores germanófilos, la propaganda alemana y el ejército. Frente a esta situación era imperioso conocer la posición de la Corona, ya que "el pueblo español, que iba olvidando su republicanismo, se ha erguido estos días con su gesto de interrogación" ${ }^{69}$. En este contexto, Luis Araquistáin pronosticó "el nacimiento de un republicanismo fecundo y eficaz como nunca lo hubo en

\footnotetext{
65 “Manifiesto de la Liga Antigermanófila”, España, 18 de enero de 1917, pp. 4-5.

${ }^{66}$ La Liga antigermanófila española", La Nación, 30 de julio de 1917, en Miguel de Unamuno, Desde el mirador de la guerra, París, Centre de Recherches Hispaniques, 1970, pp. 347-351

67 "Acto político de importancia. El discurso de Maura", La Correspondencia de España, 30 de abril de 1917, pp. 12.

68 "Manifiesto del Partido Reformista”, El Liberal, 26 de abril de 1917, p. 1.

69 "A todas las izquierdas españolas" y Luis ARAQUISTÁIN, “Una crisis germanófila”, España, 26 de abril de 1917, pp. 3-4.
} 
España"70. La movilización unitaria de las izquierdas aliadófilas se expresó en un gran mitin que contó con la presencia de unas 25.000 personas. El espectáculo demostró que la causa aliada y las izquierdas estaban unidas. En la tribuna estaban algunos de los habituales animadores de la aliadofilia, el socialismo, el republicanismo y el reformismo. Era, en cierta manera, una representación de la nueva España que Ortega había impulsado en el discurso del Teatro de la Comedia poco antes de la guerra. Más allá de los matices, todos los oradores - Álvaro de Albornoz, Andrés Ovejero, Emilio Ménéndez Pallarés, Miguel de Unamuno, Melquíadez Álvarez y Alejandro Lerroux- acordaron en que a causa de la conducta de Alemania la neutralidad ya no era una posición asumible por la sociedad. Los que defendían la neutralidad eran, en realidad, enemigos del progreso y propiciaban que el país y la nación continuaran siendo débiles, atrasados y moribundos. Únicamente uniendo sus fuerzas con las democracias España podría estar en condiciones de convertirse también en un régimen democrático ${ }^{71}$.

Pocas semanas después estalló la triple crisis que acabó por poner en jaque todo el sistema restauracionista. La crisis de finales de octubre dio como resultado el triunfo del monarca, la burguesía industrial catalana y las Juntas de Defensa. La negativa de García Prieto a que las Cortes fueran constituyentes demostró que no habría reforma constitucional a menos que los representantes dinásticos fueran literalmente barridos de las próximas elecciones. Y nada hacía pensar que las izquierdas españolas tuviesen suficiente fuerza como para conseguirlo. En definitiva, el resultado de una crisis que había de cambiar el curso de la política española había producido unas modificaciones limitadas. La Asamblea de Parlamentarios y los partidos de izquierdas, aquellos que hacía solamente medio año habían conseguido llenar la Plaza de Toros madrileña, fueron los grandes derrotados ${ }^{72}$.

Tras los sucesivos cambios de gobierno posteriores a la crisis, pareció que la llegada Maura y la constitución de un gobierno de concentración conseguiría poner fin al creciente poder de Juan de la Cierva y a la reinante inestabilidad. Sin embargo no fue así. Con la dimisión de Maura y la formación del nuevo gobierno liberal de García Prieto producida el 9 de noviembre de 1918, se esfumó la última oportunidad de restaurar el prestigio de la monarquía liberal y desapareció la esperanza de la unidad nacional. De hecho, el enésimo gabinete presidido por el marqués de Alhucemas fue un gobierno interino en espera del desenlace de la guerra. Pocas semanas después, el 5 de diciembre, el conde de Romanones volvía a ser presidente.

Este vertiginoso proceso tuvo un correlato en las reflexiones de los intelectuales. La aliadofilia dominante entre los hombres de letras españoles fue asumiendo una crítica al sistema de la Restauración cada vez más definida. Esta posición, que se había forjado a la sombra de un Ortega que había decidido salir de escena cuando el drama comenzaba a entrar en uno de sus puntos cúlmines, parecía seguir contando con la expectativa de que Alfonso XIII llevaría adelante una verdadera reforma constitucional que convertiría España en una democracia. Pero al ver que el reformismo no estaba en condiciones de ejercer una presión fuerte sobre el monarca, primero, y al constatar que este último no haría nada en favor de esta reforma, después, se radicalizó la identificación del espíritu de libertad y

\footnotetext{
70 Luis ARAQUISTÁIN, “La hora de las monarquías”, El Socialista, 1 de mayo de 1917, p. 2.

71 "El mítin de ayer. Afirmación aliadòfila y revolucionaria”, El País, 26 de mayo de 1917, pp. 1-3. Véase también Santos JULIÁ, Vida y tiempo..., op. cit., pp. 152-153.

72 Francisco ROMERO SALVADÓ, “La crisis revolucionaria española de 1917: una apuesta temeraria”, Francisco ROMERO SALVADÓ y Angel SMITH, La agonía del liberalismo español. De la revolución a la dictadura (1913-1923), Granada, Comares, 2014, pp. 57-84.
} 
democracia con las naciones aliadas. No era extraño que se mezclaran en esta posición la defensa de la democracia con fuerte diatribas contra el parlamentarismo ya que, como planteó varias veces Araquistáin, el parlamento había demostrado una y otra vez que era un instrumento de la monarquía y no un foro desde el que pudiera resolverse la crisis política en un sentido democrático ${ }^{73}$. La percepción de que Alfonso XIII tenía una responsabilidad sustancial en la política de la neutralidad y en la falta de intensidad de las respuestas de los diferentes gobernantes frente a los ataques alemanes acabó por hacerse evidente para los sectores más radicalizados del arco aliadófilo. En este proceso, los derrumbes de las monarquías de Rusia y Grecia contribuyeron decisivamente a poner en duda el papel de la Corona española. En los meses posteriores a estos procesos, Araquistáin no había cesado de cuestionar el "reinado de la interinidad" abierto con la guerra, la opción por el "esfuerzo mínimo, por la más interina de las interinidades", representada en la inacción y los constantes cambios de gabinete, y derivada de la doblemente equivocada creencia en una paz inminente y en un triunfo alemán ${ }^{74}$.

No obstante, con la guerra tocando a su fin, la emergente cultura política democrática continuaba a la espera de que Alfonso XIII emprendiera de una vez por todas las reformas constitucionales. Los intelectuales que habían convertido su aliadofilia en militancia interpretaron la derrota de Alemania como el fin de la autocracia y el triunfo de la democracia. El viejo mundo que desaparecía con la abdicación de los Hohenzollern y los Habsburgo debía dar paso, también en España, a un nuevo régimen. El propósito era claro: liquidar lo viejo y dar paso a lo nuevo. Lo viejo y lo nuevo no eran aquí categorías generacionales como antes de la guerra. Lo viejo era la autocracia, el corrupto sistema de la Restauración, y lo nuevo era la incierta democracia que el fin del conflicto mundial parecía traer a Europa ${ }^{75}$. Después del verano de 1917 todo había cambiado por completo y hacia noviembre de 1918 no se percibía un ambiente revolucionario. Más bien al contrario. Los republicanos esperaban que la monarquía cayera por sí sola y los socialistas estaban recluidos después de la fracasada huelga de agosto del año anterior. Los encargados de llevar adelante esta acción, creía Araquistáin, eran los reformistas, los únicos que hasta el momento no habían fracasado y los únicos capaces de seguir "el espíritu del tiempo, después de la victoria de los aliados, que es la victoria del liberalismo y la democracia" ${ }^{76}$. Algo parecido pensaba Ortega, aunque, a diferencia del director de España, seguía apostando -no sin cierta inocencia- por los regionalistas catalanes $y$, sobre todo, consideraba fundamental que se otorgara un papel de primer orden a las minorías intelectuales no contaminadas por la vieja política, ya que reformistas y regionalistas, no podrían gobernar si no hacían "un llamamiento a fuerzas y a hombres nuevos, ajenos a la política" ${ }^{77}$. Los reformistas, los regionalistas catalanes y los intelectuales, todos ellos ajenos a la vida política de la Restauración, eran los únicos capaces de llevar adelante una reforma constitucional y la previa convocatoria de unas Cortes Constituyentes, además de la instauración de la libertad de conciencia, la secularización del Estado y la

\footnotetext{
${ }^{73}$ En este sentido, puede verse su valoración de las elecciones de febrero de 1918, "Después de las elecciones. La victoria de la organización", España, 28 de febrero de 1918, pp. 3-4.

74 “Basta de interinidad. El error de la paz inminente”, España, 27 de diciembre de 1917, pp. 3-4.

${ }^{75}$ La dialéctica de lo nuevo y lo viejo, en Santos JULIÁ, Historias de las dos Españas, Madrid, Taurus, 2004, pp. 168170.

${ }^{76}$ Luis ARAQUISTÁIN, “Entre dos dictaduras y una revolución”, España, 7 de noviembre de 1918, p. 5.

77 “La grave política de estos días”, El Sol, 25 de noviembre de 1918, p. 1.
} 
descentralización territorial en una organización federativa, que permitiera la autonomía de aquellas regiones que lo exigiesen ${ }^{78}$.

En cierta manera, a excepción de la cuestión de la descentralización, los deseos de Ortega y Araquistáin se expresaron en un nuevo agrupamiento de los intelectuales, la Unión Democrática Española para la Liga de la Sociedad de Naciones Libres. Fue la última demostración del turbulento proceso experimentado desde 1917 al calor del cual las manifestaciones en favor de los aliados se habían ido convirtiendo en instancias simbólicas de ruptura con la España dinástica que rechazaba la cultura francesa y el espíritu de 1789. En este desarrollo, los intelectuales se habían investido de una nueva misión: defender el porvenir de la democracia en España a través de la causa aliada. Por todo ello, frente a la inminencia de la paz decidieron transformar y radicalizar la Liga Antigermanófila prohibida por el gobierno en este nuevo agrupamiento, que reivindicó la democratización de la vida española desde su manifiesto fundacional. Con el impulso de esta iniciativa, buscaban conseguir una participación española en los asuntos europeos y sentir "la sacudida espiritual" que estaba "conmoviendo las bases del mundo". España debía ser parte del nuevo escenario formado "solamente de democracias" y su democratización había de ser una "de las tareas de la sección española de la Liga de la Sociedad de las Naciones Libres". La conclusión del manifiesto era toda una llamada a la acción, "Españoles: ha llegado la hora de demostrar que somos dignos de pertenecer como pueblo y como Estado, a una comunidad de democracias civilizadas, y que no queremos seguir viviendo aislados de los dolores y esperanzas del mundo ni regidos por poderes irresponsables ante la única soberanía del pueblo" ${ }^{79}$. Como era habitual, los periódicos reformistas, republicanos y socialistas saludaron con entusiasmo esta nueva iniciativa ${ }^{80}$.

Frente al estallido de la revolución en Alemania, España volvía a confirmarse como una excepción en el contexto europeo. En la hora de la paz, había decidido reemplazar a Maura por García Prieto, y a este, por Romanones. Esto parecía ser todo, "mientras el mundo subía tan alto, España no podía descender más abajo". Una vez asumida la negativa de la monarquía a tener en cuenta a los reformistas, las izquierdas decidieron que se debía trabajar ya en una perspectiva republicana, pensó Araquistáin, "La monarquía no ha querido aceptar el único cable que podía, si no salvarla, hacer pacífico y legal su tránsito a mejor vida: el reformismo. El reformismo, después de eso y de los grandes acontecimientos ocurridos en el centro de Europa, hará bien en arrollar de nuevo su cable. Mejor será que lo reserve para lanzárselo a la república que llega de los campos de batalla" ${ }^{81}$.

Este proceso de radicalización y decepción experimentado por los sectores aliadófilos y esta división en dos de la sociedad española se observó en las principales ciudades y en la mayoría de las comarcas del país. Al concentrar la mirada en pequeños núcleos podemos ver cómo todo esto se

\footnotetext{
78 José ORTEGA Y GASSET, “Los momentos supremos. Idea de un programa mínimo", El Sol, 4 de noviembre de 1918 , p. 1.

79 “Un llamamiento. Unión Democrática Española para la Liga de la Sociedad de Naciones Libres”, España, 7 de noviembre de 1918, pp. 3-4.

80 “Un llamamiento. Unión Democrática Española”, El Sol, 8 de noviembre de 1918, p. 3; “Un Ilamamiento”, El País, 11 de noviembre de 1918, p. 2.

${ }^{81}$ Luis ARAQUISTÁIN, “Ante la crisis. Entre dos dictaduras y una revolución”, España, 7 de noviembre de 1918, p. 5; Luis ARAQUISTÁIN, "Fin de la tragedia. Paz libertadora en el mundo. Paz ominosa en España”, España, 14 de noviembre de 1918, pp. 3-5.
} 
tradujo al lenguaje y las referencias locales. En las comarcas gerundenses, continuando con el caso analizado, no solamente aparecieron en los principales periódicos los manifiestos y textos más relevantes que se han comentado -el de la Liga Antigermanófila, por ejemplo ${ }^{82}$-, también reflejaron las tensiones con los sectores germanófilos en forma de disputa por el futuro de la nación española. Así lo expresó, por ejemplo, El Autonomista de Girona en febrero de 1917, en plena tensión con Alemania por el hundimiento de barco españoles, "¿dónde está el verdadero patriotismo? ¿en los que amenazan con otra guerra civil, si España se apresta a defender, manteniendo la neutralidad hasta donde sea posible, la vida de sus hijos, o en los republicanos, que con tan alto sentido político y tanta serenidad actúan en estos momentos de tanta trascendencia para el porvenir de nuestra patria?" ${ }^{83}$. La revolución de febrero en Rusia, la entrada de los Estados Unidos en la guerra y la proyección de lo que se entendió como wilsonismo también ejercieron una notable influencia a nivel local y llevaron a que el escritor Prudenci Bertrana afirmara que se había abierto una nueva etapa que pondría fin a las tiranías en Europa ${ }^{84}$. En este marco, los regionalistas se aproximaron a los aliados mientras que los carlistas se mantuvieron en su estricta defensa de la neutralidad y, en consecuencia, se convirtieron en duros adversarios suyos. Mientras tanto, los republicanos saludaban con efusividad el mitin de la plaza de toros de Madrid de mayo ${ }^{85}$. Durante la radicalización social y política de 1917, la división entre germanófilos y aliadófilos también se manifestó como una lucha entre neutralistas e intervencionistas como en el conjunto de España. En este marco, los germanófilos españoles y catalanes llegaron a ser calificados abiertamente como "criminales" ${ }^{86}$. Con la guerra llegando a su fin y la constitución del gobierno de Maura, el 14 de julio de 1918 se convocaron elecciones para elegir un diputado provincial vacante del distrito de La Bisbal d'Empordà, en Girona. Allí pudo observarse que las consignas sobre la guerra había impactado notablemente en la sociedad ampurdanesa: "Empordanesos: en Burch té la immensa desgràcia de esser germanòfil. No el voteu", afirmó una pequeña publicación republicana de la ciudad costera de Sant Feliu de Guíxols ${ }^{87}$. Evidentemente, sus lectores y aquellos que podían sentirse referenciados con los valores republicanos -incluso aquellos que no eran capaces de leer la revista y dependían de otras lecturas previas para acceder a una composición de lugar propia- entendían entonces qué quería decir "esser germanòfil". No se trataba solamente de un debate de ideas y valores sobre la cultura, la filosofía y la ciencia de Francia o Alemania que continuaban desarrollándose en los círculos culturales e intelectuales. Era parte de la política cotidiana y de la configuración de las culturas políticas que operaban también a nivel local. Es aquí, en este proceso de lectura y construcción de una propia visión de la guerra y de su incidencia a nivel local, donde reside la potencialidad de la perspectiva que intenta proponer este artículo.

\section{A MODO DE CONCLUSIÓN: ¿UN DEBATE ENTRE INTELECTUALES?}

\footnotetext{
82 “La Liga Antigermanófila” El Autonomista, 23 de enero de 1917, p. 1.

83 "Los trogloditas", El Autonomista, 7 de febrero de 1917, p. 1.

${ }^{84}$ Prudenci BERTRANA, “El ceptre o la vida”, El Autonomista, 27 de abril 1917, p. 1.

85 "España ante el mundo. La democracia por los aliados", El Autonomista, 28 de mayo de 1917, p. 1.

86 “¿Es criminal?”, Empordà Federal, 27 de abril de 1918, p. 1.

${ }^{87}$ SILVESTRE, “D'eleccions. Lo de sempre”, L'Avi Muné, 13 de julio de 1918, p. 3.
} 
El 12 de noviembre de 1918, al conocerse la noticia del armisticio, los obreros de la fábrica Grober, la más importante de la provincia de Gerona, se manifestaron al salir del trabajo por las calles de Girona y acabaron su recorrido concentrados frente al consulado de Francia ${ }^{88}$. Un día después, las manifestaciones fueron aún más numerosas, con nuevas demostraciones públicas frente a los consulados francés e italiano y que concluyeron con una fiesta en el centro de la Unión Republicana, decorado con banderas francesas, donde el diputado Albert de Quintana pronunció un discurso ${ }^{89}$. Las celebraciones, que continuaron en la ciudad durante varios días, también se extendieron a otras poblaciones cercanas como Banyoles. En Figueres, el día 11, el alcalde republicano había anunciado el triunfo desde el balcón del ayuntamiento y había ordenado ornamentar todos los balcones de la ciudad con banderas aliadas ${ }^{90}$. Cinco días después, Empordà Federal dedicó su portada al triunfo "del derecho y la justicia" frente a los imperios. Los festejos también tuvieron lugar en poblaciones más pequeñas, como La Bisbal, donde el republicano El Programa afirmó que se había vivido un "estallido de entusiasmo delirante" ${ }^{91}$ que incluyó actuaciones musicales y manifestaciones callejeras, Sant Feliu de Guíxols, donde sonaron los acordes de La Marsellesa ${ }^{92}$ y otros pueblos. Como había advertido no sin temor el conservador Diario de Gerona, con el fin de la guerra se había abierto un nuevo período donde "lo viejo que desaparece, luchando con las nuevas realidades que salen a la luz, produce honda conmoción en todos los órdenes sociales" ${ }^{93}$.

Evidentemente, estas manifestaciones en pequeñas poblaciones alejadas de las grandes capitales europeas muestran que, como Madrid, Sevilla, Valencia o Barcelona, no habían permanecido al margen del conflicto. En este sentido, muestran -aunque no sea más que un caso regional el que aquí hemos analizado- que, a pesar de que conocemos más o menos bien las manifestaciones de alegría por el triunfo aliado que tuvieron lugar en Madrid, Barcelona y otras grandes ciudades, el estudio de casos locales nos advierte sobre la necesidad de revisar interpretaciones que han pretendido limitar los efectos del debate intelectual a los círculos culturales y a los académicos. En este sentido, como aquí se ha propuesto, un estudio de los "intermediarios culturales", es decir, de los intelectuales de capitales de provincia y ciudades medianas y de los círculos de sociabilidad política y cultural y educativa, nos puede conducir a analizar la influencia de la guerra en un sentido global que tenga en cuenta elementos tanto culturales y políticos como sociales.

El papel de estos intermediarios resulta fundamental no solamente para revisar la interpretación sobre la escasa influencia de los discursos intelectuales sobre la sociedad sino también, y fundamentalmente, para analizar un proceso mucho más complejo en el que los planteamientos de los hombres de letras se enlazaron con unas perspectivas políticas concretas. Esto sucedió, a su vez, en el

\footnotetext{
88 “La victoria del Derecho", El Autonomista, 13 de noviembre de 1918, p. 1.

89 "El triunfo de los aliados. La manifestación de ayer", El Autonomista, 14 de noviembre de 1918, p. 2.

90 “Les festes per la victoria” y PUCK, “Festa Aliadófila en 'El Jardí”, Empordà Federal, 16 de noviembre de 1918, p. 4.

91 “De la comarca. la Bisbal”, El Programa, 16 de noviembre de 1918, p. 2.

92 “La manifestació de dilluns”, L'Avi Muné, 16 de noviembre de 1918, pp. 3-4.

93 "La visión de la realidad", Diario de Gerona, 11 de setiembre de 1918, p. 1.
} 
marco de unas culturas políticas que, a pesar de encontrarse en constante desarrollo y mutación, proporcionaron a los diversos sectores sociales, también a nivel local, un marco general para comprender qué implicaba definirse como "germanófilo" o "aliadófilo" entre 1914 y 1918 y contribuyeron a consolidar en estas culturas políticas algunos elementos centrales sobre la relación entre España y Europa. Teniendo en cuenta esto, no resulta extraño que incluso después de 1918 la apelación a los años de la Gran Guerra continuara funcionando en los núcleos republicanos como una referencia para fundamentar las posiciones frente a la llegada de la Segunda República en $1931^{94}$.

Evidentemente, lejos de intentar zanjar un debate sobre la incidencia social y cultural de la Gran Guerra en nuestro país, este artículo pretende abrir una vía de trabajo sobre la relación entre el análisis desde la perspectiva eminentemente intelectual -la de los "grandes" intelectuales- y una mirada sobre los casos regionales y locales. Es éste un primer paso que espero que pueda desarrollarse con un panorama más detallado y no circunscrito exclusivamente a los casos catalanes. De conseguir esto, contaríamos con un mapa de una enorme riqueza y complejidad que, además, nos ayudaría a comprender cómo la neutralidad española, como el resto de las neutralidades durante la Primera Guerra Mundial, se convirtió en un campo de batalla, incluso en pequeños pueblos aparentemente ajenos al conflicto.

${ }^{94}$ Como ejemplo, Alexandre Deulofeu, “La República Federal Espanyola”, Empordà Federal, 2 de mayo de 1931. 